\title{
EVALUATION OF A NONEVAPORABLE GETTER PUMP FOR TRITIUM HANDLING IN THE TOKAMAK FUSION TEST REACTOR
}

\author{
M. F. Singleton \\ C. M. Griffith
}

September 28, 1978

Work pertormed under the auspices of the US Dppartment of

Energy by the UCLLL under contract number W. 7405 -ENG 48

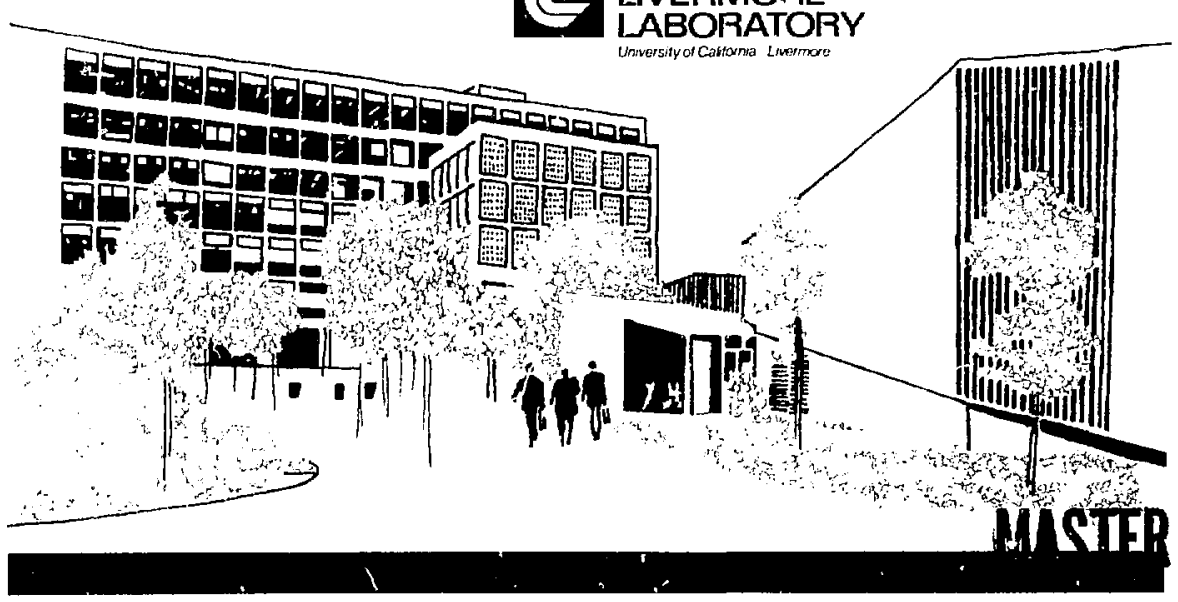




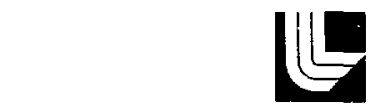

I.AWRENCE I.IVERMORE I_ABORATORY

Unversty of Calloma Livermone Calforna 94550

\title{
EVALUATION OF A NONEVAPORABLE GETTER PUMP FOR TRITIUM HANDLING IN THE TOKAMAK FUSION TEST REACTOR
}

\author{
M. F Singletun \\ C. M. Cirifith
}

Ms. date: September 28. 197s 


\title{
EVALUATION OF A NONEVAPORABLE GETTER PUMP FOR TRITIUM HANDLING IN THE TOKAMAK FUSION TEST REACTOR
}

\begin{abstract}
Lawrence Livermore Laboratory has tested and evaluated a commercially available getter pump for use with tritium in the Tokamak Fusion Test Reactor (TFTR). The pump contains $\mathrm{Zr}(84 \%)$-A] in cartridge form with a concentric heating unit. It performed well in all tests, except for frequent heater failures.
\end{abstract}

\section{INTRODUCTION}

Funson test facilities that will use tritium as a fuel are now being built. This development adds a new dimension to the operation of a fusion test facility: the safe and economical handling of a highly volatile radioattive gas. Although the problems of tritium teclinology for fusion reactors have beun anticipated for sone time." the actual building and lesting of components are now urgent concerns.

We have evaluated a commercially avaitable nonevaporable getter pump for use in the Tokamak Fusion Test Reactor (TFTR) being built at Princeton Plasma Physice Litboratory. These pumps will back up the turbomolecular pumps that remove residual deuterism and tritium from the torus after each burn. Thes are dead-end pumps designed to trap and hold the pumped gasts by absorption on Zr(84\%)-Al powder. Getlers are generally defined as metils or other materials that absorb gases to form stable compounds. The pumping speed nust be fast enough to reduce system pressure from $1 \times 10^{-3}$ to $2 \times$ 10 "Torr between each 5 -min pulse of the tokamak. About $95 \%$ of the gas injected into the torus will be absorbed by the getter furnps. When the pumps are filled to their raled capacity with hydrogen isotopes. they will be sent off-site for tritium and deuterium recovery. They will be reeycled until their rated capacity for active gases such as $\mathrm{O}_{2}$. $\mathrm{CO}$, and $\mathrm{N}_{2}$. which are permanently retained on the $Z_{r}-A l$, has been reached.

The purpose of our evaluation was to determine if thesc pumps will perform as expected in the TFTR operating mode and if any unexpected failures might occur with tritium usc. Tritium is the radioactive isotope of hydrogen and decays into $\mathrm{He}^{3}$ plus a 5.7 $\mathrm{MeV}$ beta particle. We also investigated the effect of active gas contaminants on the pumping speed and the base pressure of hydrogen isotopes at anticipated TFTR operating levels.
The performance of the pumps with hydrogen and deuterium has been previously measured, ${ }^{3}$ and the expected isotope effect on pumping speed has been observed; i.e., pumping spceds are inversely proportional to the square root of the messes. However, the pumps had not been tested previously with tritium. and tritiun pumping speeds had not been measured.

The getter pumps are manufactured by Socicta Apparecchi Elettrici c Scientifici (SAES), an Italian company, and are distributed in the U.S. by Westinghousc Electric Corporation and EAES Getters/ U.S.A. All cartridges containing the $Z_{1}-A l$ getter material are produced by SAES in Italy. We made some initial tests with pumps manufactured completely by SAES, but the majority of the tests were made on punps with Westinghouse heaters and jackets. The designs are very similar and in all cases the dimensions are the same. The pumps are composed of a Zr-Al cartridge, a heater, and an outer case or jacket with water cooling (Fig. 1). There are no moving parts. An enciosed pump has a watercooled jacket and a nude pump is simply a cartridge and heater mounted on a flange.

The SAES trade name for $\operatorname{Zr}(84 \%)-\mathrm{A}]$ is $\mathrm{St} 101$ alloy. This mixture of intermetallic compounds is powdered and pressed onto an iron substrate by a proprictary process (Fig. 2). The folded strips of powder on the substrate are arranged in concertina style at approximately 4-deg angles to form a circular eartridge with maximum surface area and trapping efficiency. This cartridge fits around the rod-shaped heating element mounted on a Conflat-style flange with electrical fecd-throughs (Fig. 3). The heater activates the $\mathrm{Zr}-\mathrm{Al}$ at $750^{\circ} \mathrm{C}$ in vactoo and maintains an operating temperature of $400^{\circ} \mathrm{C}$. The pumps operate in the $10^{-2}=$ to $10^{-10}$-Forr range. 


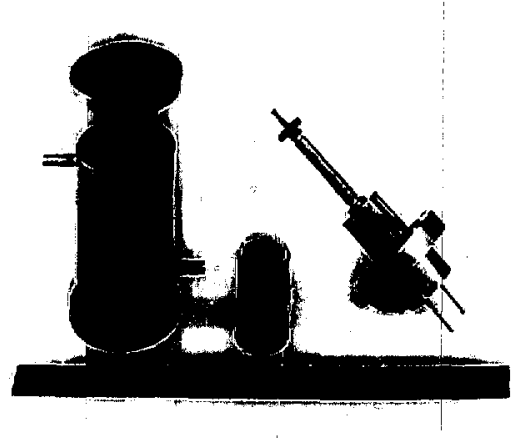

l'ig. 1. Three components of SAES getter pump: jacket, eartridge, and heater mounted on flange.

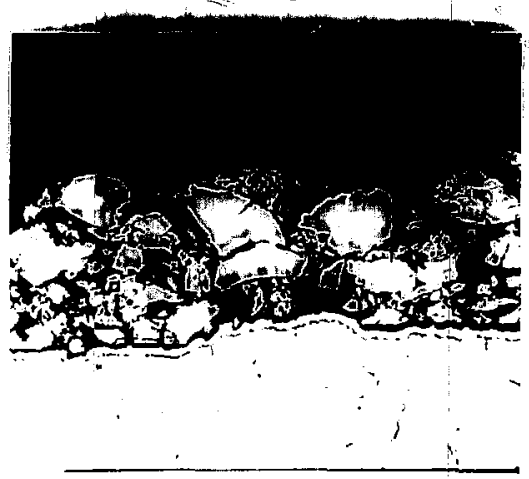

Fig. 2. Photonicrograph of $\mathrm{Zr}-\mathrm{Al}$ powder pressed onto substrat: Cor SAES cartridges (500X).

The $\mathrm{Zr}$-Al absorbs hydrogen isotopes and active gases including $\mathrm{CO}, \mathrm{N}_{2}$, and $\mathrm{O}_{2}$. The mechanism of pumping is different for the two types of gases. Hydrogen forms a solid soiution and is released when the $\mathrm{Zr}-\mathrm{Al}$ is heated in vacuo to the activation tcmperature of $750^{\circ} \mathrm{C}$. The active gases chemically combine with $\mathrm{Zr}-\mathrm{Al}$ and activation enhances the rate of diffusion of these gases ints the bulk of the getter material. ${ }^{4}$ Thus, activation of the getter increases its surface area and exposes fresh surface by diffusion of adsorbed active gases into the bulk and by removal of hydrogen isotopes. Activation is described in more detail in the SAES literature. ${ }^{5}$ Bulk material of the StI01 alloy has been tested with tritium but its performance was not satisfactory for hydrogen isotope pumping,"

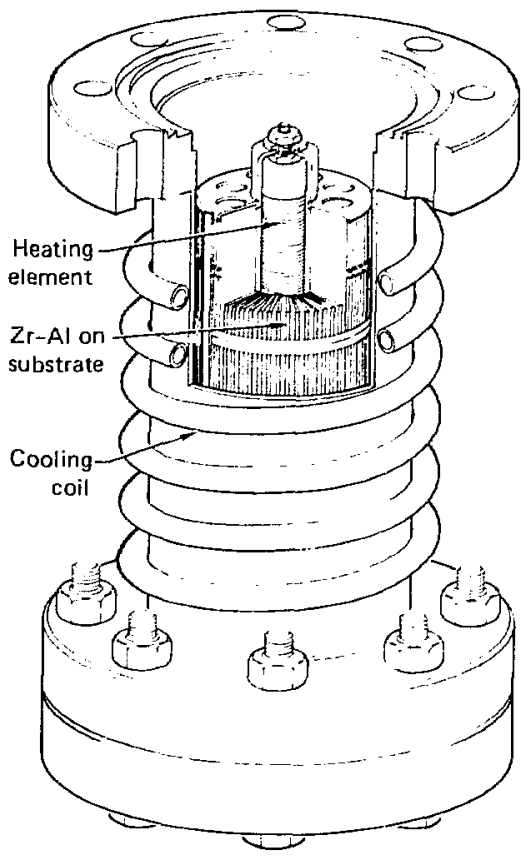

[7ig. 3. SAl:S gettor pump in stainless sted container with cooling coils.

The optimum operating temperature of the pump depends on its particular application. Temperature affects not only the diffusion rate of active gases into the bulk, but also the capacity of the $\mathrm{Zr}-\mathrm{Al}$ for hydrogen. ${ }^{7}$ Hydrogen capacity is a function of temperature and equilibrium partial pressure of hydrogen (Fig. 4). Above $400^{\circ} \mathrm{C}$, this capacily rapidly becomes too low for practical use. Temperatures as low as $150^{\circ} \mathrm{C}$ are recommended by the manufacturer for pumping pure hydrogen in small amounts. The recommended temperature range for pumping large loads of hydrogen is between 200 and $400^{\circ} \mathrm{C}$.

At $400^{\circ} \mathrm{C}$, water vapor dissociates into hydrogen and oxygen at the getter surface, and the two components are pumped separately. The hydrogen can be removed by reactivation of the cartridge. 
Methane is absorbed al a slower rate than the active gases, but the operating temperat dre is high enough to crack and pump methane and higher hydrocarbons.

As the amount of active gases increases in the carlridge, the pumpung speed decreases. Pumping speed can he incectsed by reactivation which partially restore the punp to its previous speed kecel. The de the espical method of operation and requires an atulat? pumping system for reactivaton. The atelite fases slay in the /r-Al during this process and comunue to accumulate while the hydrogen in remosed. Pamping speed drops off more quackly altu cach reactivation as the result of the bulk-up of aldute gases in the getter Io maintain a tarrly comstant putmping speed, a maximum recom-

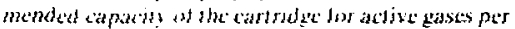
reatcuallon has been established. Ithe total recommended capacts les active gatses, which is only 2 to 3 , of the stoschometric capacity of the getter material in the ciartridge. is reached in 10 to 20 reactuatums. 1., capacity for $\mathrm{X}$ and $\mathrm{CO}$ is rated al

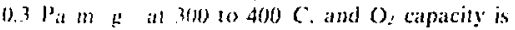
appromunately fare tomes as much."

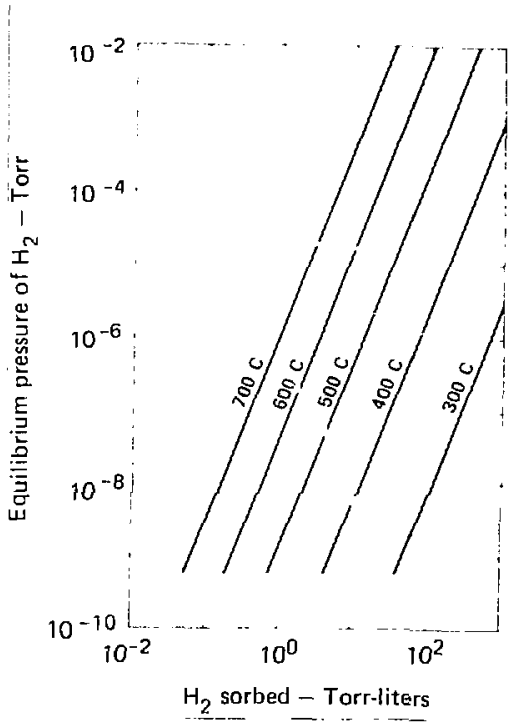

Fig. 4. l'ressurt-composition iwotherms for a $(-1) 0$ cartidge of $Z \mathbf{r} \cdot \mathrm{Al}$.

\section{PROCEDURES AND RESULTS}

The (-50) and (-100 SAES cartridges used for these evaluation studes contained a minimum of 25 and $80 \mathrm{~g}$ or $\mathrm{Zr}-\mathrm{Al}$. respectively. The manufacturer's rated capacities and pumping speeds are listed in Table 1. Some cariridges arrived in sealed cans and others were open to the atmosphere in shipping. These two methods of handling did not eause any ohservable difference in eartridge appearance or performanes. The C-50 carlridges were used for pumping speerd measurements and the C- 100 cartridges were used for buse pressure determinations. All tests were run with the enclosed-type pump.

The pumps were attached to a diffusionpumped vacuum system and the electrical feedthroughs were wired to variable transformers to regulate power to the heaters. The pumps were actiwated for $15 \mathrm{~min}$ at the suggested power setting in vacuo. Because there are no thermocouples in $t_{h}$. pumps, we relied on these power settings to produce the correct cartridge temperatures. We added two thermocouples to a $C-100$ pump located between the cartridge and the inside wall. We still could not read the act'al temperature of the cart. ridge because the tempirature gradient from the heater to the thermocouples was more than $200^{\circ} \mathrm{C}$.

Except for base pressure evaluations, during activation the pumps were evacuated with a diffusion pump. The base pressure of the diffusion-pumped systems was $10^{-6}$ Torr or less at the SAES pumps. During activation of a new cartridge, pressure rose to $10^{-2}$ Torr as the heat increased, and then fell to $10^{-4}$ Torr or less before the 15-min activation was completc. Basc pressure at the SAES pumps was about $10^{-6}$ Torr and held stcady after the diffusion pump was isolated and the power was set for operating temperature of $400^{\circ} \mathrm{C}$. After activation, the pumps were allowed to stabilize at $400^{\circ} \mathrm{C}$ for at least $30 \mathrm{~min}$ before testing.

Gas mixtures were prepared in a manifold that had been ealibrated using a portable volumecalibration system. The manifold volume was approximately 2 liters. Beforc each run, the mixture 
Table 1. Cartridge performances. ${ }^{a}$

\begin{tabular}{|c|c|c|c|c|c|c|c|c|c|c|c|c|}
\hline \multirow{3}{*}{ Cartridge } & \multirow{3}{*}{$\underset{\text { surfact, } \mathrm{cm}^{2}}{\text { Active }}$} & \multirow{3}{*}{$\begin{array}{l}\text { Getter } \\
\text { weight, b }\end{array}$} & \multicolumn{3}{|c|}{ P'umping speeds } & \multirow{2}{*}{\multicolumn{2}{|c|}{$\begin{array}{l}\text { Permanent sorption } \\
\text { eapacity ;jer resctivation. } \\
\text { Torr-liters }\end{array}$}} & \multirow{3}{*}{$\begin{array}{l}\text { Reversible } \\
\text { sorption } \\
\text { eapacity of } \mathrm{tI}_{2} \text {. } \\
\text { Torr-jiters }\end{array}$} & \multicolumn{4}{|c|}{ Pouter setlings } \\
\hline & & & (o) & $\mathrm{N}_{2}$ & $\mathrm{H}_{2}$ & & & & \multicolumn{2}{|c|}{$750^{\circ} \mathrm{C}$} & \multicolumn{2}{|c|}{$400^{2} \mathrm{C}$} \\
\hline & & & & & & Co & $v_{2}$ & & $\boldsymbol{A}$ & v & $A$ & $\mathrm{v}$ \\
\hline C-50 & 600 & 25 & - & - & - & 17 & 15 & 35 & 4.7 & $\sim 60$ & 2.3 & $\sim 35$ \\
\hline Nude & - & - & 150 & 55 & 260 & - & - & & .. & - & - & .. \\
\hline linclosed & - & - & 50) & 25 & 130 & - & - & - & - & - & - & - \\
\hline$C \cdot 100$ & 1100 & 80 & - & - & - & 30 & 25 & 90 & 10.0 & 40 & 5.0 & 18 \\
\hline Nude & - & - & 340 & 110 & 580 & - & - & - & + & - & - & - \\
\hline Enclosed & - & - & 100 & 50) & 250 & - & - & -. & - & - & - & - \\
\hline
\end{tabular}

${ }^{\mathrm{a}}$ Data taken from Westinghouse Data Sheet B-439, Westinghousc Klectric Corporation (19781.

b'Lsed at I.L.I.

was analyzed with a residual gas analyzer (UT] I00-C) connected to the manifold through a variable leak valve. Pressure in the manifold was measured with MKSS Baratron gages (1- anr' 1000-Torr head\$).
The entire system was designed and built using ultra-high vacuum techniques and all-melal construction, predominatinty 316 stainless steel fsec Fig. 5).

\section{PUMPING SPEED}

To determine pumping speed, two C-50 SAES pumps wert allached through $10-\mathrm{cm}-0 . \mathrm{d}$. gatevalves to the ends of a large-dianeter, 40-liter stainless steel tank (Fig. 6). This configuration allows the pump inlet, a 4.4-cm-diam opening, to be the conductance-limiting path during pumping. The calculated conduclance of the inlet is 130 liters/s. The 40-liter tank was connected to an approximately 2-liter manifold through a Granville-Phillips motordriven leak valve (Series 216) controlled by an MKS pressure controller (Model 99A). During pumping speed determinations the controller maintained a constant pressure at the SAES pump by regulating flow from the high-pressure manifold side to the tank side. The tank was also connected to a portable diffusion pump system for activation and pumpdown.

New cartridges were used to determine pumping speeds of deuterium and hydrogen. The cartridges used for tritium pumping speed determinations had seen orly a trace amount of aetive gases and had been used for scveral deuterium and incrt gas pumping speed determinations. After use with tritium, all cartridges were removed and stored in containers in an a rgon-filled glove-box. The tritium was lef on the cartridges so that aging effects can be studied if the interest arises.

We measured pumping speeds at constant pressures of about $10^{-3}$ Torr. The 40 -liter tank was filled to the test pressure and the controller was set on automatic before opening the gate valie to one of the SAES pumps. The test pressure was detected with a Varian dual-range ion gage mounted on the 40-liter tank and corretions were made for the ionization probubility of eatch test gas. The pressure: drop in the manifold was neasured with a 1000-1 orr MKS Baratron gage.

We calculaled pumping specds as an iverage value over a designated time period." When pumping speeds decreased with time. we conipared identica! time intervals. Most pumping speeds werc compared over a $3-\min$ interval. We used the following pumping speed formuli:

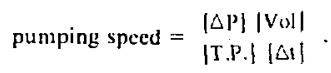

where $\triangle P$ is pressure drop in tbe manifold in Torr. Vol is ealibrated volume of inanifold in liters. T.P. is test pressure at the SAES pump in Torr. and it is length of time of test in seconds.

If inert gases are present in the mixture. they are not absorbed by the SAES pumps and accumulate in the tank during pumping speed measurements. The amount of inert gas rapidly builds up in the tank so that the automatic controller shuts off completely and the run is terminated. Helium- 3 was an inert gas 


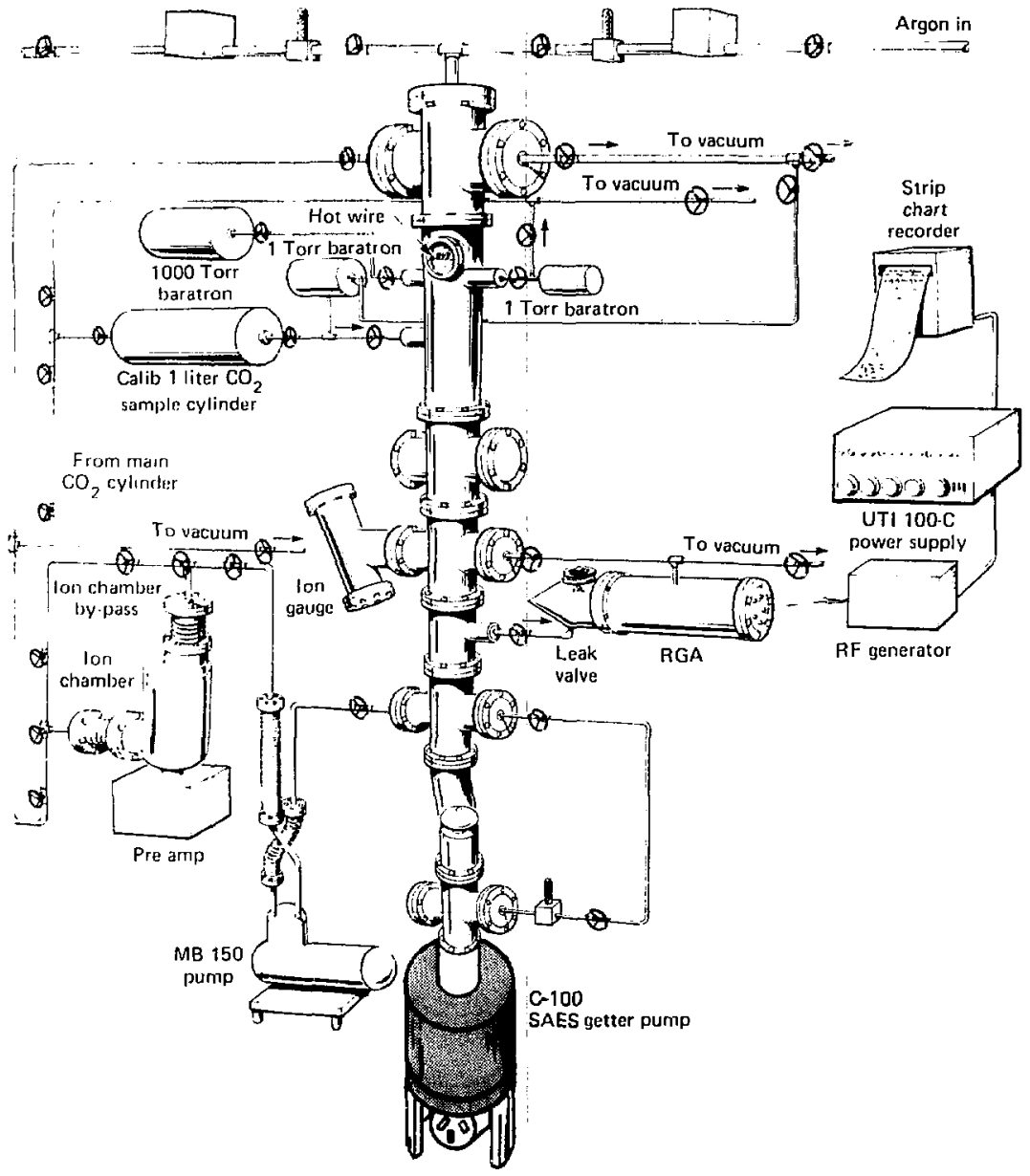

Fig. 5. Calibrated manifold with SAES pump. 


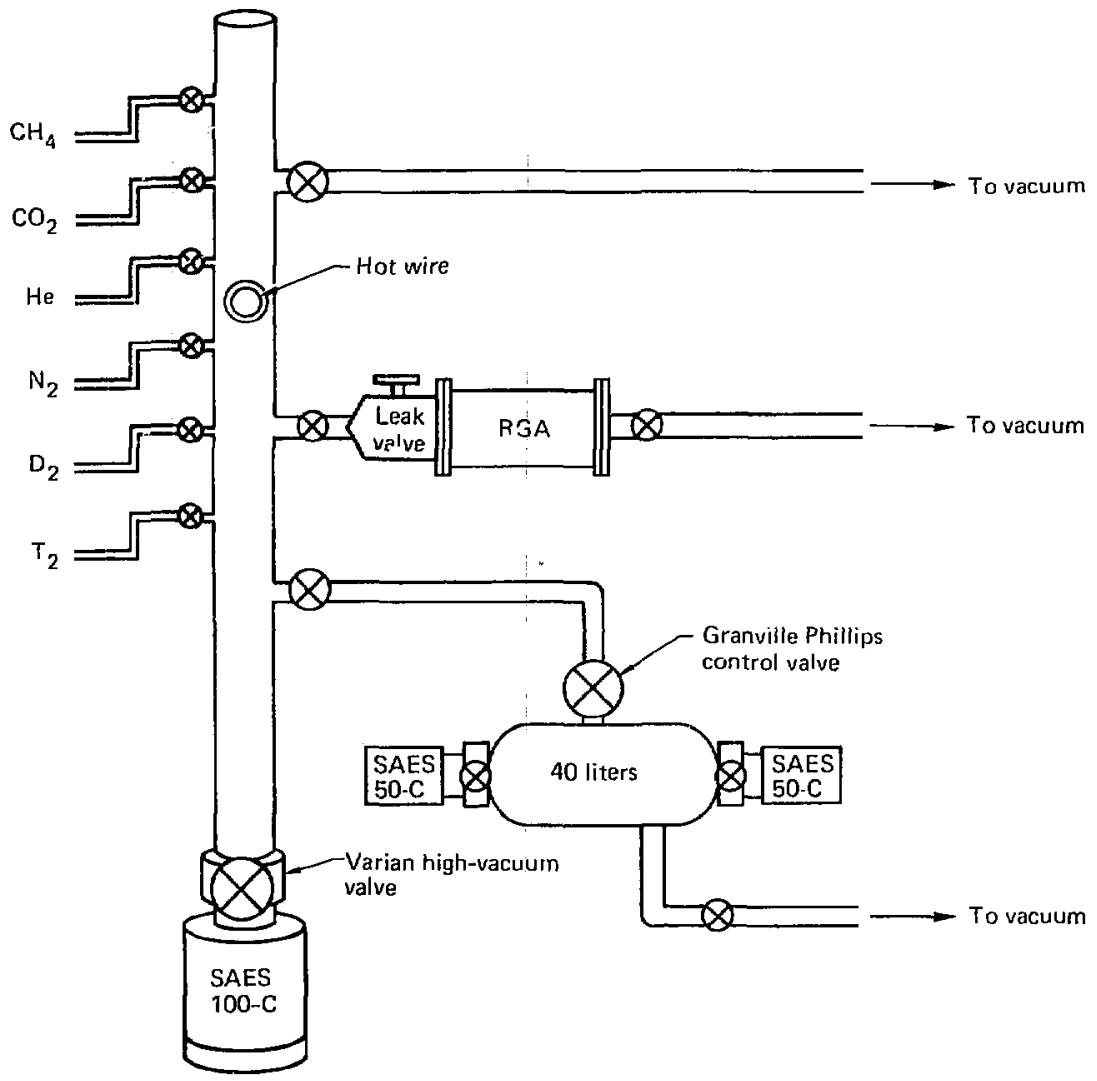

Fig. 6. A scenubly for pumping speed meusurements.

contaminant in all the tritium pumping speed measurements. The lowest $\mathrm{He}^{3}$ contamination was less than $1 \%$. For comparison, we measured the pumping speeds of hydrogen and deuterium with less than $1 \% \mathrm{He}^{4}$. The effect of the inert gas accumulation can be seen as a decrease in pumping speed with time (Table 2).

We measured the pumping speeds of pure hydrogen and pure deuterium several times with reprodueible results. Several runs were made with deuterium containing from 2 to $9 \%$ argon and with tritium having $3 \%$ He . All of these runs were unsatisfactory because the pressure controller shut off too quiekly as a result of inert gas build-up in the 40-liter tank.

The pumping speeds of three active gases were measured on the same cartridge. Mcasurements were done in duplicate with the two C-50 SAES pumps on the 40 -liter tank. The active gases were run in the following order with reactivation of the 
Table 2. Pumping specd for C-50-size SAES pump."

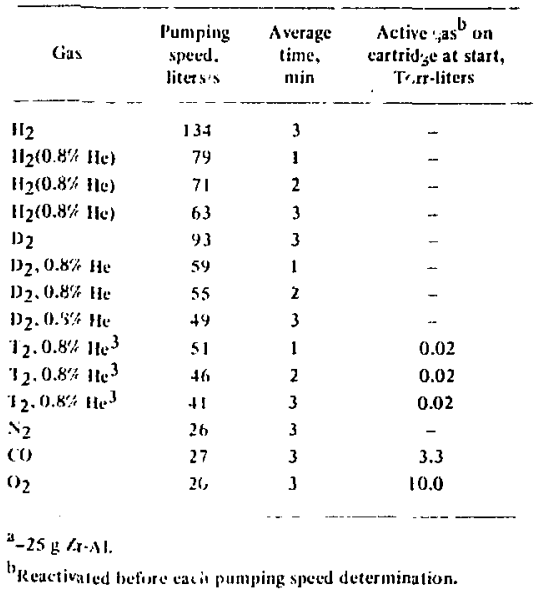

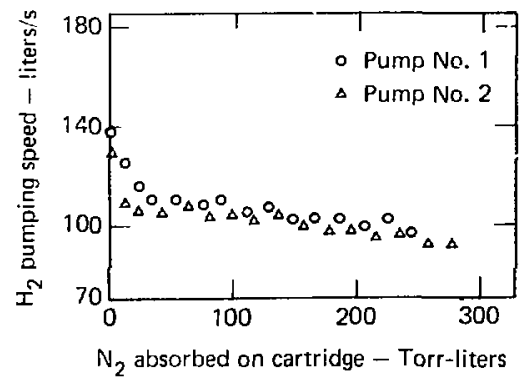

Fig. 7. $1 \mathrm{H}_{2}$ pumping speed at $1.2 \times 10^{-3}$ Torr $v_{s} \mathrm{~N}_{2}$ load on punp. Pumps were reactivated before tacli measurement. cartridges between each test (the amount of active gas added to the two cartridges during each test is included in pareiatheses): $\mathrm{N}_{2}$ (3.15 and 3.63 Torrliters). $\mathrm{CO}$ (2.91 and 3.09 Torr-liters), and $\mathrm{O}_{2}(2.82$ and 1.93 Torr-liters).

We used the same pair of cartridges to measure the effect of active gas load on hydrogen pumping speed (which we had measured before any active gases were put on the eartridges). We measured hydrogen pumping speed again after the three active fises were tested and the cartridge was reaetivated. $W_{e}$ performed a series of 14 more tests alternating hydrogen and nitrogen pumping speed determinations with reactivation of the cartridges after each addition of hydrogen and after each addition of nitrogen. For each test, approximately $18 \mathrm{~T}$ orr-liters of nitrogen were added to the pump'i and they were still working when the tests were terminated with almost 250 Tor-liters of active gases on each cartridge ( $\mathrm{Figs}$. 7 and 8 ). The eartridges had been reactivated at least 30 time', and still appeared to be cunctioning very well. They did not show any visible signs of deterioration when removed.

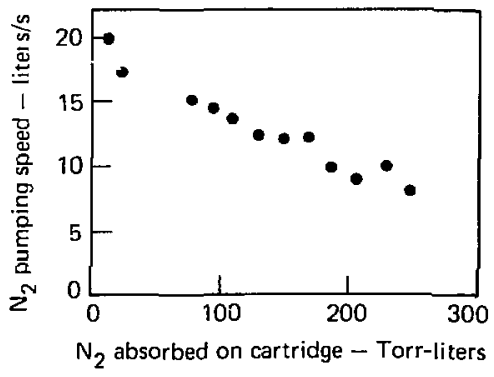

Fig. 8. $N_{2}$ pumping specd at $6 \times 10^{-3}$ Torr ys $N_{2}$ load on pump. 


\section{BASE PRESSURE}

A C-100 SAES pump was connected to the calibrated manifold through a Varian all-metal bakeable vacuum valve. A Varian Millitorr gage vias located on the pump side of the valve, so the pressure at the SAES pump could be monitored costisuously. This pump was used for base pressure evaluation studies.

The TFTR will operate in a 5-min pulse mode and unused gas must be removed from the torus between each pulse. SAES pumps will be used to back up the turbomolecular pumps that evacuate the torus. The base pressure at the SAES pumps must stay helow $10^{-3}$ Torr for 60 consecutive pulses according to present design criterid.

It is anticipated that SAES pumps will be activated at around $10^{-3}$ Torr in the TFTR. This is considerably higher than we used with the diffusionpumped systems. To determine the effect of activation on pump performance in this pressure range, we used roughing pumps for activation and reactivation for all base pressure experiments. If the apparatus had not been pumped previously with a diffusion pump, the base pressure of the roughpumped system was about $10^{-4}$ Torr. To simulate TFTR conditions, the roughing pump was shut off during actiyation when the pressure had peaked out and was dropping back through the $10^{-3}$ Torr range. When the SAES pump stabilized at $400^{\circ} \mathrm{C}$, the base pressure was in the $10^{-5}$ Torr range. This method of activation appears to be satisfactory if $10^{-5}$ Torr is a low enough base firessure for backing the turbomolecular pumps.

In the first base pressure experiment, an activated pump at $2 \times 10^{-5}$ Torr was opencd to the manifold which contained deuterium at 81 Torr $(150$ Torr-liters). The pressure dropped to $2 \times 10^{-4}$ Torr in $1 \mathrm{~min}$ and to $1.5 \times 10^{-4}$ Torr in $2 \mathrm{~h}$. Without reactivation, a serond addition of deuterium at 390 Torr (722 Torr-liters) caused the pressure drop outlined in Table 3. We observed that single additions of large amounts of hydrogen to the SAES pumps result in much slower returns to stable base pressure. The calibrated volume of the manifold is 1.852 liters and the C- 100 pump volume is 0.691 liters.

The second base pressure experiment simulated, as closely as possible, the TFTR operating mode. A mixture of deuterium with low-level impurities was prepared. The impurity level ivas based on data from the Princeton Large Torus (PLT) exhaust gas mixtures. The major contaminants by volume were $1 \% \mathrm{CO}$ and $1 \% \mathrm{CH}_{4}$ (methane) which would result in
Table 3. $D_{2}$ pressure vs time after single addition of 722 Torr-liters.

\begin{tabular}{rl}
\hline Time, min & Pressure, Torr \\
\hline 0 & 390 \\
1 & $6 \times 10^{-3}$ \\
2 & $1.8 \times 10^{-3}$ \\
12 & $6.4 \times 10^{-4}$ \\
120 & $5.8 \times 10^{-4}$ \\
2160 & $4.2 \times 10^{-4}$ \\
\hline
\end{tabular}

tritiated methanes in TFTR. "Table 4 lists the quantity of each component of exhaust gas that could be pumped onto an array of tweive C-500 SAES cartridges as proposed for use in TFTR. The twelve cartridges contain approximatcly $4600 \mathrm{~g}$ of $\mathrm{Zr}$-Al. Table 4 also lisis the percent of cach component in a similar gas mixture prepared for the SAES pump evaluations.

A new, activated cartrioge pumped a total of 170 Torr-liters of this gas mixture in 60 consecutive 5 -min pulses. The manifold was filled to a pressure of 1.5 Torr containing approximately 2.8 " Torr-liters of the mixture per pulse. The initial base pressure at the SAES pump was $1.2 \times 10^{4}$ Torr and the tinal pressure after 60 pulses was $6.1 \times 10^{\circ}$ Torr. Within seconds after opening the pump to the manifold, base pressure was established for each pulse. Adding this quantity of the gas mixture in small increments at $400^{\circ} \mathrm{C}$ did not appreciably affect the pumping spr d or equilibrium base pressures.

Table 4. Projected gas loading for a TFTR getter purmp $^{3}$ (using 12, C-500 cartridges).

\begin{tabular}{lccc}
\hline Gas & $\begin{array}{c}\text { Load, } \\
\text { Torr-licers }\end{array}$ & $\begin{array}{c}\text { Volumie, } \\
7\end{array}$ & $\begin{array}{c}\text { Experimental } \\
\text { volume, }{ }^{\text {b }} \%\end{array}$ \\
\hline $\mathrm{H}_{2}$ & 3 & 0.03 & - \\
$\mathrm{D}_{2}$ & 1400 & 15.4 & 47.99 \\
$\mathrm{~T}_{2}$ & 7500 & 82.5 & - \\
$\mathrm{CO}$ & 90 & 1.0 & 0.99 \\
$\mathrm{CH}_{4}$ & 90 & 1.0 & 0.99 \\
$\mathrm{~N}_{2}$ & 1 & 0.01 & 0.0097 \\
$\mathrm{O}_{2}$ & 1 & 0.01 & 0.0092 \\
$\mathrm{CO}_{2}$ & 1 & 0.01 & 0.010 \\
\hline
\end{tabular}

\footnotetext{
Based on PLT data.

${ }^{b}$ Used at LLL.
} 
We conducted a similar base-pressure experim:nt usi.lg tritium in the first and last phises. Between the two tritium pulses, deuteriurn with $\mathrm{I} ; \mathrm{CO}$ and $1 \mathrm{C} ; \mathrm{CH}_{4}$ was added in one large anount equal to 58 pulses of the previous run. The extra-high-purity tritium had a $\mathrm{He}^{2}$ content of less than $0.100^{2}$. The starting hase pressure of the SAES pump was $11 \times$ 10" Torr.

For the first pulse, the manifold was filled with tritium to a pressure of 1.78 Torr (3.02 forr-liters) and the Varian salse was opened. The pressure in the manifold immediately dropped to $1.8 \times 10^{4}$ Torr and remained steads. I his fairly large increase in hase pressure was attributed to the $H_{c}{ }^{2}$ in the tritium. We used the $\mathrm{RG}$ (is to analyze the oserpressure gas and found it to be predominantly at 3 amu. The Varian valve was elosed and the manifo!d was evacuated and filied with deuterium plus $1{ }^{\circ}, \mathrm{CO}$ and $1 \mathrm{C}, \mathrm{CH}_{4}$ at 94.03 Torr (159.6 Torr-liters? which is equivalent to 58 smaller pu!ses. The salse was then opened and the pump and manifold based out at $1.6 \times 10^{3}$ Torr in 3 min. The pump reached equilibrium more slou:!y because of the large amoun of deuterium added in one pulse. Wc attributed the slight drop in final pressure from the presious aritium-pulse final pressure to the fact thix: the $\mathrm{HC}^{\circ}$ in the SAES pump expanded into the extra manifold volume. $A$ final pulse with tritium at 1.83 Torr (3.11 Torr-liters) in the manifold based oat at $3 \times 10^{4}$ Torr in a few seconds after opening up to the SAES pump. Again. the increast: in hase pressure can be attributed to the HL" in the Iritium.

\section{CONCLUSIONS AND RECOMMENDATIONS}

The pe-tormanec of SAES sinol alloy for pumping hydrogen isotopes was excellent. On a short-term basis. tritium did not appear to adversely affect the pumps. We did not investigate the longterm effects of radiolysis and $1 \mathrm{l} \mathrm{e}^{3}$ production in the cartridges.

The He overpressure is the pemps is a problem that must be further investigat d, in the oFTR design. The auxilliary vacuum system used to activate the p:imps could remove $\mathrm{He}^{3}$ overpressure and sivert it to the molecular-sieve clean-up system. There would be very low les als of tritium in this effluent gas so it could unt be relee sed wit hout further processing.

Methane was satsfactorily pumped by the SAES pumps at the level of contamination anticipated for the TFTk. A hot wire, placed in the manifold for cracking hydrocarbons, was nol needed for the l\% methane in deutcrium pumping experiments. We did not irivestigate the effect of prolonged or high-level tnethane absorption on pumping specd.

The SAES pumping speeds for hydrogen isotopes and active gases demonstrated by iur tests are morc than satisfactory for the TFIR as long as the recommended capacity of active gases is not cxceeded. It is the active gas conient of the cartridge that limits its usefulness because it affects both pumping specd and base pressure. The pumping speeds of hydrogen and nitrogen are plotled as a function of active gas capacity in Figs, 7 and 8 . The manufacturer's total rated eapacity for the C-50 cartridge is 140 Torr-liters of active gases and reactivation is required after each addition of 17 Torr-liters. We conducted tests to 250 Torr-liters of active gatses on a (-50 cartridge and fcund the initial hydrogen pumping speeds after reactivation vere still quite satisfactury fer the JFTR. A sharp drop in hydrogen pumping speed occurred while adding the lirst 40 Torr-liter" of active gases. After this initial decrease the hydrogen pe zping speed leveled off as a function of active gas capacity, but the nitrogen pumping speed continued to drop at a faster rate. Howcver. the pumping speed drops off morc quickly after cach atddition of attive gas.

We tested the base pressure of a cartridge under the conditions of one complcic losding at the TFTR using the active gas concaminants projected from PLT. The base pressure proved sery steady and the only problem we anticipate is the $\mathrm{He}^{\prime}$ overpressure that we mentioned previously. Base pressure enly increased from $1.2 \div 17^{\circ}$ 10 $6.1 \times 10^{\prime}$ "Torr with deuterium containing $1 \mathrm{C} ; \mathrm{CO}$ and $\mathrm{I} ; \mathrm{CH}_{4}$ during one compiete TFTR loading cycle. Variations of this experiment using tritium and or larger single loadings were all sutisfactory. We did not test the cartridges for the reycling that is planued for the TFIR. e.g. tritium removal and repeated usc over an extended time period.

We heared a SAES pump loaded with tritium to activation temperatures and did not jetect any tritium diffusion through the walls of the sump. This is no doubt caused by the placement $s$ the heater at the center of the pump and the water eooling of the outer jacket. However. we found the heaters to be most unsatisfactory. They failed repeatedly for several reasons; c.g. the heatcr element shorted ou: the cursuit opened. the support rod 
broke, or insuiators cracked. A reliable heater is essential for tritium use because of the difficultics in repairing a tritium-conlaminaled pump. Wespent a great deal of our time during this study repairing heaters or ehanging pumps with taibed heaters. A new SAES pump con!iguration is now available with panels heated by direct current through the substrate material. We did not test this design but it may eliminate the healer problems we encountered and be a more reliable pump for tritium use.

sinme concern has been expressed aboust the danger of fire should an air leak develop in the $S A E S$ pump system. We did not have an opportunity to check this possibility. The manufacturer states that the cartridges will not burn below $560^{\circ} \mathrm{C}$ and that the only time there is a possihility of a pump catching fire is during the activation process." At the llFl $R$. only new or recycled cartridges containing no appreciahle amounts of tritiun will be activated. Tritium will he removed from the cartridges at an off-site location. The cartridges will be returned for reuse several time.s. We anticipate that detectable leyels af tritium would be released from a catridge if exposed to air after absorption of tritium, but the release, would be small and the air would quickly passivite the getier matcrial. The pumps absorb hydrogen quite rapidly even at room temperature, and we demonstrated this was also true for tritium. We loaded a C- 100 eartridge to twice-rated capacity with $T_{2}$ at room temperalure.

The pumping speed deterninations of all three hvdrogen isotopes make it possible for the first time to compare tritiurn speeds to hydrogen and deuterium. Pure hydrogen and deuterium pumping speeds measured in our laboratory agreed very closely with the values measured and reported by the manufacturer. Our method of calculating pumping speeds was different. but hydrogen pumping speeds are constant at $400^{\circ} \mathrm{C}$ over a large-eapacity rarige, so the resuits were essentially the same. All the duplicate purnping speed measurements agreed within $5 \%$ of each other.

The pumping speed of the $\mathrm{C}-50$ model was conductance-limited to 130 liters/s by the area of the inlet. This is the hydrogen pumping speed value reported by the manufacturer for the C -50 pump and
Table 5.

\begin{tabular}{|c|c|c|c|}
\hline $\begin{array}{c}\text { Jxilopes } \\
\text { of } \\
\text { byurogen }\end{array}$ & $\begin{array}{c}\text { Colculated } \\
\text { inversc } \\
\text { sq. rotst } \\
\text { ratio }\end{array}$ & $\begin{array}{l}\text { P'uriphng } \\
\text { speed } \\
\text { ratio. } \\
\text { 3-min runs }\end{array}$ & $\begin{array}{l}\text { SAl:S } \\
\text { literature }\end{array}$ \\
\hline$\| I_{2}$ us $]_{2}$ & 1.41 & 1.44 & 1.43 \\
\hline${ }^{*} \mathrm{D}_{2}{ }^{\prime} \mathrm{s}^{*} \mathrm{~T}_{2} *$ & 1.2 & 1.2 & - \\
\hline$* \| I_{2} v_{s} T_{2} *$ & 1.7 & 1.5 & - \\
\hline${ }^{*} \mathrm{HI}_{2} \mathrm{~s}_{\mathrm{s}} \mathrm{D}_{2}$ & 1.4 & 1.3 & - \\
\hline
\end{tabular}

$*$ Witli $0.8 \% 1 \mathrm{tl}$.

it is very close to our average measured value of 134 liters, s. The pure deuterium pumping speed moisured on this pump was 93 liters s.

The tritium used for pumping speed determinations contained about $0.8 \% \mathrm{Hec}^{7}$. Inert contaminants causc a decrease in punping speed with time as previously explained. The tritium pumping speed varicd from 51 to $4 \mathrm{l}$ litcrs.s for $t$ - and $3-\mathrm{min}$ intervals. For comparison. we ran deuterium and hydrogen pumping speeds with $0.8, \mathrm{He}^{3}$ as an incrt gas contintinate. The pumping speeds measured for deutcrium with helium were 59 and 49 liters s for 1- ald 3-min intervals. For hydrogen with helium, the speeds were 79 and 63 liters $s$ for 1 and $3 \mathrm{~min}$.

The isotope effect on pumping speed is predicted to be proportional to the inverse square root of the ratio of the masses. The SAES pump results are putlined in Table 5. Our hydrogen and deuterium data compare favorahly with the SAES values. Tritium and deuteriun show excellent agreement with the predicted values.

The results of our studies indicate that Stlot alloy in cartridge form is a satisfactory getter for tritium at temperatures between 25 and $400^{\circ} \mathrm{C}$. depending on the level of active gas contamination. The netsured pumping speeds are more than adequate for the TFFR operating mode. All the eartiridges we tested were reliable. The heaters caused several problems and should be redesigned for reliability. 


\section{ACKNOWLEDGMENTS}

We wish to thank and acknowledge other members of the tritium facility for their help on this project. Ed Mahan built the experimental apparatus with an eye to aesthetics as well as utility, willingly and cheerfully aided by Don Fearon, Roger Decker, and Gary Young. For technical advice we especially thank Dick Alire and Steve Steward. For advice on tritium handling techniques, and for tritium supply, we thank both Terry Biel and Roy Tsugawa.

The assoriation with Mr. Rober Soave of Grumman Aerospace was always very amiable, and his suggestions and support were much appreciated.

\section{REFERENCES}

1. R. G. Hickman, Tritium in Nuclear Fusion Pow'tr, Lawrence Livermore Laboiaiury, Rcpt. UCRL-75546 (1974).

2. A. Barosi, I. A. Giorgi, and L. Rosai, "Charactcristics of SORB-AC Non-Evaporable Getter Cartridges and Their Potential Use in Fusion Reactors," in Proce. of Int. Conference on Radiation Effects and Tritium Techmolesg. for Fusion Reactors. Gatlinburg, Tennesset, October 1975. NTIS Conf-750989. IV 203 (1976).

3. B. Ferrario et al., in Proc. of the 9th SOFT; Garmisch, Germany, EUR 960251 (1976).

4. I. A. Giorgi and F. Ricca, Suppl. al Nuovo Cime'no I. Serie 1612 (1963).

5. B. Kind! and E. Rabusin, Suppl. al Nuovo Cimento 536 (1976).

6. C. W. Schoenfeld and L. A. West, "Tritium Removal: A Preliminary Evaluation of Several Getters," in Proc. of Im. Conference on Radiation Effects and Tritium Technology'for Fusion Reactors. Gatimburg. Tennessee. October 1975. NTIS Conf-750989. 111, 482 (1976).

7. St-I0I Data Sheet, G 77620, SAES Getters/U.S.A., Colorado Springs, Culorado (1977).

8. L. Rosai, B. Ferrario, and P. della Porta, Behavior of SORB-AC Wafer Pumps in Plasma Machines," $J$. Vac. Sci. \& Tech. 15, 746-50 (1978).

9. S. Dushman, Scientific Foundations of Vacuum Techniques (John Wiley \& Sons, New York, 1959).

10. W. F. Brunner, Jr. and T. H. Batzer, Practical Vacium Techniques (Robert E. Krieger Publishing Co., New York, 1974).

11. W. H. Beattic. "The Radiolysis of Mixtures of Carbon Monoxide and Hydrogen," Int. Journal of Chemical Kinetics 5, 333-343 (1973). 